\title{
Gambaran Spiritualitas Kerja Dan Pemaknaan Pada Pekerjaan Pada Pasukan Oranye Kota DKI Jakarta
}

\author{
Clara Moningka, S.Psi., M.Si ${ }^{1,}$ Pasha Nandaka Fauziah ${ }^{2}$, Yulius F. Angkawijaya, M.Psi, \\ Psikolog ${ }^{3}$.
}

\author{
Program Studi Psikologi Universitas Pembangunan Jaya \\ ${ }^{1}$ Email: clara.moningka@upj.ac.id \\ ${ }^{2}$ Email: pasha.nandaka@student.upj.ac.id \\ ${ }^{3}$ Email: yulius.fransisco@upj.ac.id
}

\begin{abstract}
This research is conducted to find out the spirituality of work in "pasukan orange" (orange troop) of DKI Jakarta. The spirituality of work can be defined as the employees' self-understanding as a spiritual being whose soul (the soul) requires maintenance even in a work place. It encompasses how work experience has goals and meaning, including the feelings of relating with others or with their community at work. The spirituality of work has three dimensions including meaningful work, sense of community, and internal life. Based on the results of the study, the majority of orange troops (53.24\% from 340 worker) tends to have a high spirituality of work. Based on the response from the open ended questionnaire constructed by Moningka and Angkawijaya (2017) indicated that the orange troop interpreted their work as job that really useful for others. The results of the t-tests indicating that there is no difference in the spirituality of work based on age, gender, education level, marital status and number of children.
\end{abstract}

Keywords: orange troop, the menaing of work, spirituality of work

\begin{abstract}
Abstrak : Penelitian ini dilakukan untuk mengetahui gambaran spiritualitas kerja pada pasukan oranye DKI Jakarta. Spiritualitas kerja dapat dijelaskan dengan pemahaman diri pekerja sebagai mahkluk spiritual yang jiwanya (the soul) memerlukan pemeliharaan di tempat kerja. Hal ini melingkupi bagaimana pengalaman kerja memiliki tujuan dan memiliki makna, termasuk perasaan terhubung dengan orang lain atau dengan komunitasnya di tempat kerja. Spiritualitas kerja memiliki tiga dimensi meliputi pekerjaan yang bermakna (meaningful work), rasa memiliki komunitas (sense of community), dan kehidupan internal (inner life). Berdasarkan hasil penelitian, mayoritas anggota pasukan oranye memiliki spiritualitas kerja yang cenderung tinggi. Hal ini ditunjukan dengan responden dengan spiritualitas kerja tinggi berjumlah 181 orang (53.24\%) dan responden dengan spiritualitas kerja rendah berjumlah 159 orang (46.76\%). Berdasarkan open ended questionnaire yang dikonstruksi oleh Moningka dan Angkawijaya (2017) juga diperoleh respon bagaimana mereka memaknai pekerjaannya seperti pekerjaan sebagai sesuatu yang berguna bagi orang lain. Berdasarkan hasil uji tambahan menunjukkan bahwa tidak ada perbedaan spiritualitas kerja berdasarkan usia, jenis kelamin, pendidikan terakhir, status pernikahan dan jumlah anak.
\end{abstract}

Kata Kunci : pasukan oranye, makna pekerjaan, spiritualitas kerja 


\section{PENDAHULUAN}

DKI Jakarta sebagai ibukota Negara memiliki masalah yang begitu kompleks. Permasalahan-permasalahan utama yang kerap dilaporkan warga DKI Jakarta adalah mengenai sampah, parkir liar, iklan liar, berbagai pelanggaran, fasilitas umum yang rusak, pedagang kaki lima yang sulit ditertibkan, kemacetan, dan masalah banjir (Adiputra, 2017). Berbagai permasalahan yang terjadi di Jakarta mendorong pemerintah membuat program-program untuk menanggulangi permasalahan ini. Salah satu program gubernur kota DKI Jakarta adalah pembentukan petugas prasarana dan sarana umum (PPSU).

PPSU adalah gabungan pekerja yang melakukan penanganan prasarana dan sarana umum yang diangkat berdasarkan perjanjian kontrak kerja dalam jangka waktu tertentu (Pergub, 2015). Gagasan awal mengenai PPSU pertama kali dicetuskan oleh Gubernur DKI Jakarta Basuki Tjahaja Purnama. Beliau merasa terganggu dengan keadaan Jakarta yang kotor, saluran air yang tersumbat, dan jalanan yang rusak. Pada tahun 2013, Basuki Tjahaja Purnama yang saat itu menjabat sebagai Wakil Gubernur menugaskan Biro Tata Pemerintahan untuk membentuk satuan petugas kebersihan yang bertugas di di wilayah permukiman penduduk di tiap kelurahan (Putera, Aziza, Rudi, Purba \& Cahya, 2017). Pada tahun 2015, Basuki Tjahaja Purnama mengeluarkan peraturan Gubernur (pergub) Nomor 169 tahun 2015 mengenai penanganan prasarana dan sarana umum tingkat kelurahan (Yulika, 2017). Pergub ini disusun untuk mengoptimalkan pelayanan kepada masyarakat. Pada tahun 2016 PPSU terbentuk secara resmi.

Setelah PPSU dibentuk, Basuki Tjahaja Purnama membagi bidang pekerjaan PPSU menjadi 7 bidang pekerjaan yang ditandai dengan warna seragam yang berbeda-beda. Ketujuh bidang pekerjaan yang dibentuk oleh gubernur kota DKI Jakarta ini lebih dikenal dengan pasukan warna-warni. Istilah pasukan warna-warni ini sendiri dipopulerkan oleh masyarakat. Jenis pasukan warna tersebut diantaranya adalah pasukan biru (bertugas untuk menghadapi permasalahan saluran air), pasukan hijau (bertugas menjaga dan membersihkan taman kota), pasukan oranye (berkaitan dengan kebersihan lingkungan kota), pasukan hitam (bertugas mengurus jenazah tanpa identitas), pasukan ungu (bertugas dengan masalah kesejahteraan sosial), pasukan putih (berkaitan dengan berkas permohonan perizinan) dan pasukan kuning (berkaitan dengan pembangunan kota).

Dalam penelitian ini, peneliti tertarik untuk meneliti pasukan oranye yang kerap menjadi sorotan warga. Fenomena petugas oranye yang menghadapi bahaya untuk membersihkan sampah di goronggorong membuat pasukan ini menjadi penting peranannya dalam membersihkan kota. Seorang petugas yang diwawancarai oleh mengatakan bahwa tugas mereka dihargai oleh masyarakat (Cahya, 2017). Bagi petugas tersebut, dulu mereka seringkali dipandang sebelah mata dan pekerjaan mereka kerap dianggap pekerjaan rendahan. Setelah apa yang mereka lakukan berdampak positif, mereka menjadi lebih dihargai oleh masyarakat. Peneliti telah melakukan wawancara pribadi dengan beberapa orang terkait pandangan mereka pekerjaan yang dianggap rendah. Responden pada penelitian ini mengatakan bahwa bekerja sebagai pasukan oranye bukan pekerjaan yang hina. Narasumber mengatakan bahwa bekerja sebagai pasukan oranye merupakan suatu pekerjaan yang mulia dan berjasa. Pekerjaan ini memang berhubungan dengan sampah atau saluran air yang kotor, namun hal ini bukan sesuatu yang dapat dilakukan oleh banyak orang. Narasumber mengatakan bahwa pekerjaan yang dilakukan oleh pasukan oranye berdampak positif bagi warga Jakarta karena kota yang dulu kotor sekarang menjadi bersih (komunikasi personal, 2017).

Peneliti juga melakukan wawancara yang dilakukan oleh dengan 6 (enam) orang 
narasumber yang berinisial $\mathrm{M}$ (55 tahun), AF (43 tahun), IP (38 tahun), A (30 tahun), MZ (43 tahun), dan F (25 tahun) terkait pengabdian mereka menjadi pasukan oranye Kota DKI Jakarta. Rata-rata responden, sudah dua tahun bekerja sebagai anggota pasukan oranye. Alasan mereka bekerja pada dasarnya adalah untuk memenuhi faktor ekonomi. Responden juga menyatakan bahwa selain memenuhi kebutuhan ekonomi, mereka juga merasa bertanggung jawab untuk membersihkan lingkungan kota. Responden mengatakan bahwa mereka merasa sudah mersa menyatu dengan pekerjaan mereka, sehingga mereka pun juga enggan mengganti pekerjaan mereka dengan pekerjaan lain.

Penelitian ini juga berusaha mengidentifikasikan pemaknaan pasukan oranye terhadap pekerjaan mereka. Berdasarkan hasil wawancara, responden menunjukkan bahwa anggota pasukan oranye memaknai nilai-nilai yang ada dalam pekerjaan mereka. Fenomena ini merupakan perwujudan dari spiritualitas kerja. Spiritualitas kerja merupakan kondisi yang memungkinkan kinerja karyawan dapat meningkat karena individu memaknai pekerjaannya (Widyarini, 2011).

\section{KAJIAN PUSTAKA Spiritualitas}

Spiritualitas adalah sikap atau perilaku yang mencakup pencarian makna, tujuan dan pemenuhan secara moral yang berkaitan dengan diri, orang lain, mencakup alam semesta, dan sesuatu yang lebih tinggi (Furman, Benson, Canda \& Grimwood dalam Ajala, 2013). Staude (dalam Ajala, 2013) melihat spiritualitas sebagai proses transformasi, integrasi berbagai aspek kehidupan (fisik, emosional, pekerjaan, intelektual, dan rasional). Spiritualitas sangat berkaitan dengan kreativitas, cinta, pengampunan, kasih sayang, kepercayaan, penghormatan, kebijaksanaan, keyakinan, dan rasa kesatuan (Ajala, 2013).

Istilah spiritualitas seringkali disalahartikan, dilihat sebagai sesuatu yang konteksnya sama dengan agama, keyakinan tertentu, aturan moral, dan tradisi-tradisi (Widyarini, 2011). Cacioppe (dalam Widyarini, 2011) menegaskan bahwa spiritualitas bukanlah sesuatu yang formal, terstruktur, dan terorganisir. Spiritualitas tidak sama dengan agama (Harrington dkk, dalam Widyarini 2011). Marques (dalam Widyarini, 2011) menjelaskan bahwa dengan spiritualitas, individu dapat melihat ke dalam batin, kesadaran akan nilai-nilai universal, sedangkan agama formal lebih berfokus pada ritus (tata cara keagamaan) formal dan kitab suci. Sesuai dengan pernyataan itu Cacioppe (dalam Widyarini, 2011) mengatakan bahwa agama formal memiliki orientasi eksternal, sedangkan spiritualitas mencakup seseorang yang memandang ke dalam batinnya. Keadaan ini dapat dimiliki oleh semua orang, baik yang religius maupun tidak.

\section{Spiritualitas Kerja}

Spiritualitas di tempat kerja dijelaskan oleh Ashmos dan Duchon (2000) sebagai pemahaman diri pekerja yang jiwanya memerlukan oenyegaran dan mendapatkan pemeliharaan di tempat kerja. Dalam hal ini individu mengalami pekerjaannya sebagai suatu tujuan dan sesuatu yang memiliki makna; termasuk bagaimana ia dapat memaknai hubungannya dengan individu lain dalam lingkungan kerja (dalam Widyarini, 2011). Secara singkat, Ashmos dan Duchon (2002) mendefinisikan spiritualitas di tempat kerja sebagai pengakuan bahwa pekerja memiliki kehidupan internal (inner life) yang baik karena pekerjaan yang bermakna.

\section{Komponen Spiritualitas Kerja}

Teori spiritualitas kerja menurut Ashmos dan Duchon meliputi: 1) Kehidupan batin (inner life); 2) Makna dan tujuan dalam bekerja (meaningful work); 3) Perasaan terhubung dengan komunitas (community). Berikut penjelasan Ashmos dan Duchon (2000) mengenai tiga komponen spiritualitas di tempat kerja, yaitu: 


\section{a. Inner Life}

Spiritualitas di tempat kerja merupakan penemuan bahwa pekerjaan merupakan wadah mengekspresikan berbagai aspek yang dimiliki seseorang, bukan sekedar pemenuhan tugas fisik dan intelektual, namun bagaimana pekerjaan memberikan kepuasan. Kepuasan ini yang pada akhirnya menghasilkan perilaku yang lebih produktif

b. Meaningful Work

Setelah mengenal elemen spiritual dalam diri pekerja, diperlukan penerimaan bahwa para pekerja perlu terlibat dalam pekerjaan yang memberikan makna terhadap hidupnya

\section{c. Sense of Community}

Spiritualitas di tempat kerja bukan hanya meliputi keadaan batin dan kebermaknaan pekerjaan, namun bagaimana individu dapat hidup terkoneksi dengan orang lain; khususnya yang berhubungan dengan pekerjaannya. Perasaan menjadi bagian dari komunitas merupakan suatu elemen esensial bagi perkembangan spiritualitas.

\section{METODE PENELITIAN}

Metode penelitian yang digunakan dalam penelitian ini adalah penelitian kuantitatif. Sampel pada penelitian ini adalah individu yang bekerja sebagai anggota pasukan oranye Kota DKI Jakarta yang berstatus aktif. Subjek penelitian yang digunakan dalam penelitian ini berjumlah 340 orang anggota pasukan oranye. Teknik sampling yang digunakan dalam penelitian ini adalah teknik non-random sampling atau non-probability sampling yaitu convenience sampling.

Penelitian ini melakukan adaptasi aitem skala spiritualitas kerja yang dikembangkan oleh Widyarini (2011), yang terdiri dari 22 butir pernyataan yang merupakan skala Likert dengan 4 pilihan jawaban. Peneliti telah melakukan evidence based of test content berupa proses forward translate dan back translate yang dilakukan oleh penterjemah Magister Sastra Inggris, uji keterbacaan dengan 10 orang responden dan expert judgement dari 2 orang yang dianggap kompeten dalam Psikometri atau pengukuran psikologi. Contoh butir pernyataan dapat dilihat pada tabel 1 .

Tabel 1. Butir pernyataan

\begin{tabular}{l}
\hline Contoh butir peryataan \\
\hline 1.Saya merasa bersemangat karena pekerjaan \\
yang saya lakukan \\
2.Teman kerja saya saling memberikan \\
dukungan
\end{tabular}

Butir pernyataan pada alat ukur ini memiliki rentang corrected item total correlation yang baik, karena berada di > .30. Dalam hal ini corrected item total correlation berhubungan dengan daya diskriminasi item, dimana item dapat membedakan antara kelompok yang memiliki spiritualitas kerja yang cenderung tinggi dan sebaliknya. Untuk skala ini dihitung dengan menggunakan Cronbach Alpha, dengan koefisien reliabilitas alat sebesar 0.928. Pada penelitian ini juga diidentifikasi respon-respon mengenai pemaknaan responden terhadap pekerjaan mereka.

\section{HASIL PENELITIAN}

Hasil analisis menunjukkan bahwa responden dengan tingkat spiritualitas kerja tinggi berjumlah 181 responden $(53.24 \%$ dari total responden penelitian) dan responden dengan tingkat spiritualitas kerja rendah berjumlah 159 responden $(46.76 \%$ dari total responden penelitian). Dapat disimpulkan bahwa mayoritas responden memiliki tingkat spiritualitas kerja yang cenderung tinggi. Responden dengan tingkat inner life tinggi berjumlah 195 responden $(57.35 \%)$ dan responden dengan tingkat inner life rendah berjumlah 145 responden $(42.65 \%)$. Dengan demikian, mayoritas responden memiliki inner life yang cenderung tinggi. Responden dengan tingkat meaningful work tinggi berjumlah 213 responden $(62.65 \%)$ dan responden dengan tingkat meaningful work rendah berjumlah 127 responden (37.35\%). Dengan demikian, mayoritas responden 
memiliki meaningful work yang cenderung tinggi.

Responden dengan tingkat sense of community tinggi berjumlah 225 responden atau $(66.17 \%)$ dan responden dengan tingkat sense of community rendah berjumlah 115 responden (33.83\%). Dengan demikian, mayoritas responden memiliki sense of community yang cenderung tinggi. Peneliti juga melakukan uji beda dengan membedakan skor berdasarkan varibel demografis. Perhitungan ini menunjukkan bahwa tidak terdapat perbedaan spiritualitas kerja berdasarkan usia, jenis kelamin, pendidikan terakhir, status pernikahan, dan jumlah anak. Hasil selengkapnya dapat dilihat pada tabel 2.

Tabel 2. Hasil Penelitian

\begin{tabular}{lcc}
\hline Kategori & $n$ & $\%$ \\
\hline Spiritualitas Kerja & & \\
Tinggi & 181 & $53.24 \%$ \\
Rendah & 159 & $46.76 \%$ \\
Inner Life & & \\
Tinggi & 195 & $57.35 \%$ \\
Rendah & 145 & $42.65 \%$ \\
Meaningful Work & & \\
Tinggi & 213 & $62.65 \%$ \\
Rendah & 127 & $37.35 \%$ \\
Sense of Community & & \\
Tinggi & 225 & $66.17 \%$ \\
Rendah & 115 & $33.83 \%$ \\
\hline
\end{tabular}

Berdasarkan open ended questionnaire dapat ditemukan beberapa respon mengenai bagaimana mereka memaknai pekerjaannya. Sebanyak 206 responden $(60.58 \%)$ responden memaknai pekerjaan mereka secara internal. Mereka menganggap bahwa pekerjaan mereka berguna dan bermanfaat bagi kehidupan mereka dan bagi orang lain. Pekerjaan ini dianggap sebagai pekerjaan yang mulia.

\section{SIMPULAN}

Hasil skor analisis dari penelitian ini mengenai spiritualitas kerja secara umum menunjukkan bahwa sebanyak $53.24 \%$ anggota pasukan oranye memiliki tingkat spiritualitas kerja tinggi dan sebanyak $46.76 \%$ anggota pasukan oranye memiliki tingkat spiritualitas kerja rendah. Persentase ini diperoleh dengan membandingkan skor rerata empirik dengan rerata teoritik data penelitian. Berdasarkan hasil skor analisis spiritualitas kerja secara keseluruhan menunjukkan bahwa anggota pasukan oranye cenderung memiliki spiritualitas kerja yang tinggi. Sedangkan, tingkat spiritualitas kerja berdasarkan dimensi inner life menunjukkan bahwa sebanyak $57.35 \%$ anggota pasukan oranye memiliki tingkat inner life tinggi dan sebanyak $42.65 \%$ anggota pasukan oranye memiliki tingkat inner life yang rendah. Berdasarkan hasil skor analisis spiritualitas kerja dengan dimensi inner life menunjukkan bahwa anggota pasukan oranye cenderung memiliki spiritualitas kerja yang tinggi. Data dapat dilihat pada tabel 3.

Tabel 3. Rerata dan Standar Deviasi

\begin{tabular}{lccc}
\hline \multirow{2}{*}{ Variabel } & \multicolumn{3}{c}{ Empiris } \\
\cline { 2 - 4 } & $M_{t}$ & $M_{e}$ & $S D$ \\
\hline Spiritualitas Kerja & 55 & 74 & 7 \\
Inner Life & 20 & 27 & 2.67 \\
Meaningful Work & 17.50 & 23 & 3 \\
Sense of Community & 17.50 & 23 & 2.17 \\
\hline
\end{tabular}

Hasil skor analisis selanjutnya dari penelitian ini berdasarkan variabel demografis responden yaitu usia, jenis kelamin, pendidikan terakhir, status pernikahan, dan jumlah anak. Secara keseluruhan, berdasarkan variabel demografis yang disebutkan menunjukkan bahwa anggota pasukan oranye yang memiliki tingkat spiritualitas kerja yang cenderung tinggi. Berikutnya, tingkat spiritualitas kerja berdasarkan dimensi 
meaningful work menunjukkan bahwa sebanyak $62.65 \%$ anggota pasukan oranye memiliki tingkat meaningful work tinggi dan sebanyak $37.35 \%$ anggota pasukan oranye memiliki tingkat meaningful work rendah. Berdasarkan hasil skor analisis spiritualitas kerja dengan dimensi meaningful work menunjukkan bahwa anggota pasukan oranye cenderung memiliki spiritualitas kerja yang tinggi.

Selanjutnya, tingkat spiritualitas kerja berdasarkan dimensi sense of community menunjukkan bahwa sebanyak $66.17 \%$ anggota pasukan oranye memiliki tingkat sense of community tinggi dan sebanyak $33.83 \%$ anggota pasukan oranye memiliki tingkat sense of community rendah. Berdasarkan hasil skor analisis spiritualitas kerja dengan dimensi sense of community menunjukkan bahwa anggota pasukan oranye cenderung memiliki spiritualitas kerja yang tinggi. Penelitian ini menunjukkan bahwa terdapat spiritualitas kerja pada pasukan oranye yang dianggap sebelah mata oleh banyak orang karena jenis pekerjaan mereka yang berkaitan dengan membersihkan sampah. Penelitian ini juga menunjukkan bahwa tidak terdapat perbedaan spiritualitas kerja pada berdasarkan usia, jenis kelamin, pendidikan terakhir, status pernikahan, dan jumlah anak.

\section{SARAN}

Peneliti memberikan saran untuk penelitian selanjutnya agar lebih memperbanyak serta memperdalam teori mengenai spiritualitas kerja. Peneliti menyarankan untuk penelitian selanjutnya untuk melakukan penelitian pada pasukan warna kota Jakarta lainnya. Pasukan warna kota Jakarta sendiri masih tergolong baru dan memiliki fenomena tersendiri, maka dari itu dengan melakukan penelitian terkait pasukan warna ini memberikan sumbangan penelitian baru bagi literatur-literatur Psikologi Indonesia. Akan lebih baik apabila penelitian selanjutnya dapat dikaitkan dengan konstruk lain seperti budaya organisasi.
Bagi pemerintah, Peneliti menyarankan agar lebih memperhatikan dan meningkatkan kebutuhan dari anggota pasukan oranye dan petugas lain yang memiliki pekerjaan serupa dalam hal kejelasan kontrak kerja dan benefit yang dapat mereka peroleh.

Peneliti juga menyarankan bagi masyarakat selaku penikmat kinerja pasukan oranye agar lebih menghargai peran pasukan oranye. Berdasarkan hasil wawancara dan respon jawaban responden, responden mengemukakan bahwa masyarakat cenderung tidak memperhatikan kebersihan lingkungan Kota Jakarta. Mereka kerap membuang sampah sembarangan pada area yang sudah dibersihkan oleh anggota pasukan oranye. Padahal, di setiap area disediakan tempat untuk membuang sampah. Mereka mengatakan bahwa sudah membersihkan area tugas yang diberikan tetapi tidak lama kemudian akan kotor kembali karena ulah masyarakat sendiri. Dalam hal ini penghargaan terhadap pekerjaan mereka oleh masyarakat luas juga diperlukan.

\section{DAFTAR PUSTAKA}

1. Adiputra, R., 10 Permasalahan Jakarta Yang Paling Banyak Dilaporkan, 2017, diakses dari http://www.esquire.co.id/article/2017/4/ 4398-10-Permasalahan-Jakarta-yangPaling-Banyak-Dilaporkan.

2. Ajala, E. M., The Impact Of Workplace Spirituality And Employees Well-Being At The Industrial Sector: The Nigerian Experience, The African symposium, 3 (13), 3-13, 2013.

3. Ashmos, D. P., \& Duchon, D. (2000). Spirituality At Work: A Conceptualization And Measure, Journal of management Inquiry, Vol. 19, No. 2, pp. 134-145, 2000.

4. Cahya, K. D., "Pasukan oranye: kami merasa dihargai dan dianggap oleh pak ahok", 2017, diakses dari http://megapolitan.kompas.com/read/20 17/03/03/11292841/.pasukan.oranye.ka 
mi.merasa.dihargai.dan.dianggap.oleh.p ak.ahok.

5. Peraturan Gubernur Provinsi Daerah Khusus Ibukota Jakarta, Penanganan Prasarana Dan Sarana Umum Tingkat Kelurahan, Jakarta, 2015.

6. Putera, A. D., Aziza, K. S., Rudi, A., Purba, D. O., \& Cahya, K. D., Pasukan Penjaga Ibu Kota, Kompas, 2017.

7. Sugiyono, Metode Penelitian Manajemen, Bandung: Alfabeta, 2014.

8. Yulika, N. C., Pasukan Pelangi Senjata Ahok - Djarot Ubah Jakarta, 2014, Diakses dari http://news.liputan6.com/read/2913172/ pasukan-pelangi-senjata-ahok-djarotubah-jakarta

9. Widyarini, N., Perilaku Kewargaorganisasian Dan Kinerja Dalam Tugas, Dengan Predictor Kepemimpinan Spiritual, Iklim Spiritualitas Kerja, Dan Budaya Organisasi Terbuka. (Disertasi tidak dipublikasikan). Yogyakarta: Universitas Gadjah Mada., 2011. 